\title{
Microstructures and Metallographic Characterization of Superalloys
}

\author{
Patrice Berthod
}

\author{
Institut Jean Lamour, Campus ARTEM, 2 allée André Guinier 54000 Nancy, France
}

\begin{abstract}
Superalloys are metallic alloys with specific microstructures and atoms in solid solution allowing good mechanical and chemical properties at high temperature, typically higher than $1000^{\circ} \mathrm{C}$. They present many different types of \{matrix - precipitates\} combinations which can be characterized at each step of their elaboration, by specifying the chemical compositions and the crystalline network of the phases present. After test on a sample (laboratory scale), or after the deterioration in service of a component leading to its replacement by a new one (industrial scale), the superalloys constituting these pieces are often usefully examined. This aims to specify the changes occurred in their microstructures as well as in their surface or sub-surface, due to the endured thermal, mechanical and chemical solicitations. These characterizations can be simply done using basic low-magnification optical microscopic examinations. Other means such as electronic microscopy and other advanced apparatus may be usefully involved for further investigations. After a brief history about superalloys, an overview of the phenomenological aspects of their mechanical and chemical solicitations during their use at high temperature, the metallographic techniques which are usually employed to characterize them are presented and illustrated in the case of a chosen family of superalloys.
\end{abstract}

Keywords: Superalloys, microstructures, optical microscopy, electronic instruments.

\section{INTRODUCTION}

Until the middle of the twentieth century the industrial processes or aeroengines working at high temperature used ceramic materials and also metallic alloys [1]. Most of the latter ones displayed essentially high temperatures of fusion start and resistances against mechanical and chemical solicitations at high temperature. This can be obtained by a refractory microstructure constituted by an austenitic network and by the presence of high amounts in chromium. This element is known for its ability to form efficient protective oxides. Notably for the aeroengines (Figure 1) for which improved performances were constantly wished [2], higher and higher operation temperatures were demanded. The reason was that reaching higher temperatures for the gas entering the turbines (TET) was necessary for better efficiencies for civil planes and for rather better specific powers for military aircrafts. Thus the turbine entry temperatures (TET) progressively increased from about $700^{\circ} \mathrm{C}$ during the second world war to typically $1500^{\circ} \mathrm{C}$ in the 1990 's. The same trend was observed for the TET of the industrial gas turbines, with an increase from about $700^{\circ} \mathrm{C}$ again near 1960 up to about $1300^{\circ} \mathrm{C}$ near 1990 . The increase in temperature and then in both high temperature creep and corrosion rates [2] induced a necessary development of new alloys, much more complex than the first nickel-chromium alloys. Improvements were realized in many fields: chemical compositions with the appearance of new elements

Address correspondence to this article at the Institut Jean Lamour, Campus ARTEM, 2 allée André Guinier 54000 Nancy, France; Tel: (+33) 3727427 29; E-mail: patrice.berthod@univ-lorraine.fr among them many were difficult to introduce in the alloys. This led to take into account their high tendency to oxidize, and consequently to develop fabrication processes of the alloys more complex than the initial fusion in air which was usually used for the initial simple $\mathrm{Ni}-30 \mathrm{Cr}$ alloys. Second, new post-solidification heat treatments were found to obtain optimized microstructures. Third, new elaboration routes were imagined and developed to allow synthesizing alloys which were not possible to elaborate by foundry. In parallel, the means of characterization evolved to allow specifying the particular microstructures and the enhanced high temperature properties of the newly obtained alloys. These ones were named "superalloys" thanks to their formidable increased capabilities at considerably increased severe conditions of use in terms of high temperature and mechanical/chemical solicitations.

This chapter precisely aims to present, not exhaustively, the means of microstructure characterization used in the case of the superalloys, from the simple ones (e.g. optical metallography) to more sophisticated techniques, by illustrating them with specific examples, often based on a special family of superalloys very useful for a pedagogic purpose: the carbides-strengthened chromia-forming nickel or cobalt-based superalloys. This presentation will be necessarily preceded by paragraphs shortly reminding the main lines of the elaboration and chemical compositions of superalloys, the degradation that they usually endure during their use in aeroengines (as well as in some industrial processes) and how their behaviors can be specified by laboratory tests in separated domains of solicitation. Expertises of real 

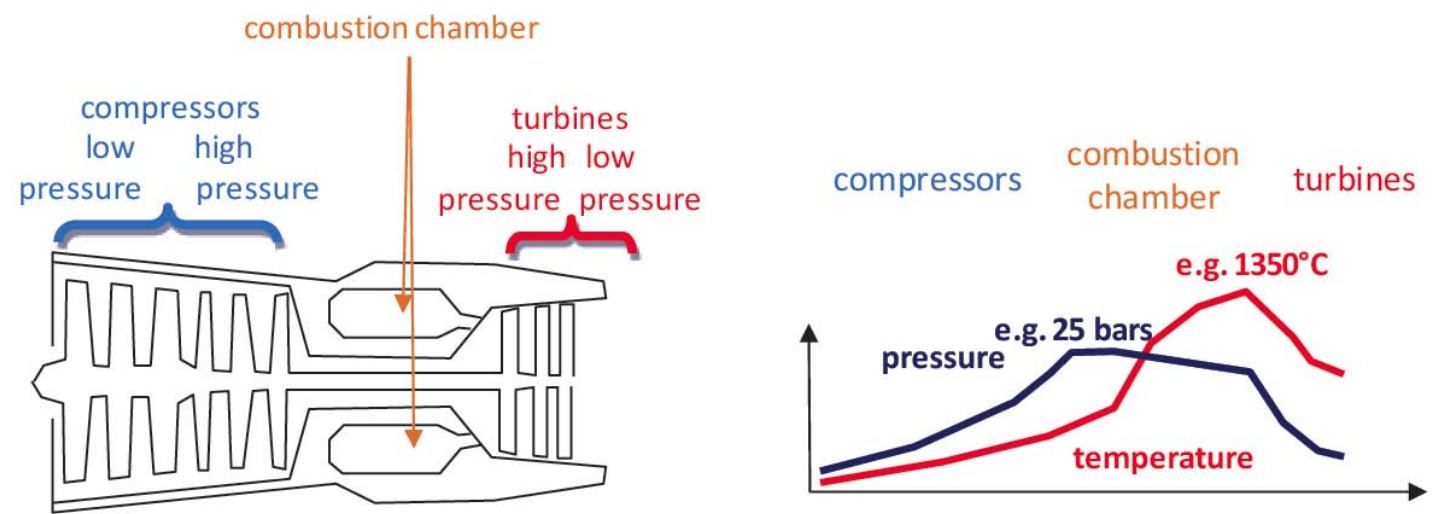

Figure 1: Schematic representation of an aeroengine and of the qualitative evolution of both pressure and temperature from entry to exit of the engine.

pieces in end of life as well as of studied samples are the main subjects of the use of the characterization techniques which will be presented.

\section{OVERVIEW OF THE MAIN SOLICITATIONS ENDURED BY THE HOTTEST PARTS IN TURBINES OR INDUSTRIAL PROCESSES}

In aeronautic or terrestrial turbines, the combustion cans and turbine vanes are exposed to particularly high temperatures but they do not endure centrifugal stresses, in contrast with the rotating turbine blades and disks. These ones are exposed to high temperatures, intense mechanical stresses and hot corrosion. Typically, blades are exposed to elevated temperatures, to oxidation by gases (e.g. over $950^{\circ} \mathrm{C}$ ) or corrosion by condensed salts or by CMAS liquids (between 600 and $950^{\circ} \mathrm{C}$ ), and to rather moderate centrifugal stresses (between 100 and $600 \mathrm{MPa}$ ) which induce creep to which the alloy - often a cast nickelbased superalloy cooled by internal gas circulation - is exposed at temperatures ranging between 650 and $1100^{\circ} \mathrm{C}$. The disks are usually subjected at essentially oxidation at moderate temperatures (e.g. $650^{\circ} \mathrm{C}$ ) but endure more intensive stresses than the blades. In power generation or glass industry plants or in waste incinerators oxidation and corrosion by various gas combining air, water vapor, sulfur oxides, $\mathrm{HCl}$, carbon oxides, ... and molten sulfates or the worked molten glasses. The contact with such substances leads to more or less severe chemical deteriorations, oxidation, corrosion, metal dusting, ... simultaneously with thermal fatigue or creep. A noticeable case is the spinners used to fabricate glass wool for thermal and/or acoustic insulation since such tools are simultaneously subjected to oxidation by hot air as well as by hot burner's combustion gases, corrosion/erosion by molten glasses and creep induced by centrifugal stresses.

\section{Creep}

The creep phenomenon, which may affect every metallic alloys if subjected to almost constant stresses at temperature high enough (i.e. at least more than the half of the absolute temperature of fusion start of the concerned alloy), is due to the creation and movement under the shear stresses induced at the grain scale by the external mechanical forces applied to the component [3]. After a first stage of rapid but decelerated deformation (primary creep) during which the dislocation network becomes more and more dense (Franck-Read's sources and mechanism), the deformation rate becomes low and constant (secondary creep). The duration of this second stage of creep represents the main part of the lifetime (which is usually considered for the time sizing), except in the cases of stress or temperature, particularly high (Figure 2). After coalescence of crystal steps, several microcracks may start propagating, this resulting in an acceleration of the macroscopic deformation (tertiary creep) followed by the final rupture of the piece if this one was stressed in traction (Figure 3 ).

\section{High Temperature Oxidation and Corrosion}

Many types of atmospheres or gas mixes can be encountered by metallic alloys at high temperature. In presence of oxygen metals are necessarily oxidized [4] $\left\{a\right.$. $\left.\left.M+(b / 2) \mathrm{O}_{2} \rightarrow \mathrm{M}_{\mathrm{a}} \mathrm{O}_{\mathrm{b}}\right)\right\}$ but oxidation can also occur by water vapor $\left\{\mathrm{M}+\mathrm{b} . \mathrm{H}_{2} \mathrm{O} \rightarrow \mathrm{MO}_{\mathrm{b}}+\mathrm{b} \cdot \mathrm{H}_{2}\right\}$, by carbon oxide $\left\{\mathrm{M}+\mathrm{b} . \mathrm{CO}_{2} \rightarrow \mathrm{MO}_{\mathrm{b}}+\mathrm{b} . \mathrm{CO}\right\}$, chlorine $\left\{\mathrm{M}+(\mathrm{b} / 2) \cdot \mathrm{Cl}_{2} \rightarrow \mathrm{MCl}_{\mathrm{b}}\right\}$, or sulfur-containing gases $\{\mathrm{M}$ $\left.+\mathrm{b} . \mathrm{H}_{2} \mathrm{~S} \rightarrow \mathrm{MS}_{\mathrm{b}}+\mathrm{b} . \mathrm{H}_{2}\right\}$ or $\left\{3 . \mathrm{M}+\mathrm{b} . \mathrm{SO}_{2} \rightarrow \mathrm{MS}_{\mathrm{b}}+\right.$ $2 . \mathrm{MO}_{\mathrm{b}}$ \}. Such reactions may occur in aeroengines, steam turbines or waste incinerators, with often combined effects. During their cooling accompanying their circulation toward the exit of the engine, the combustion gasses may condense on the following 


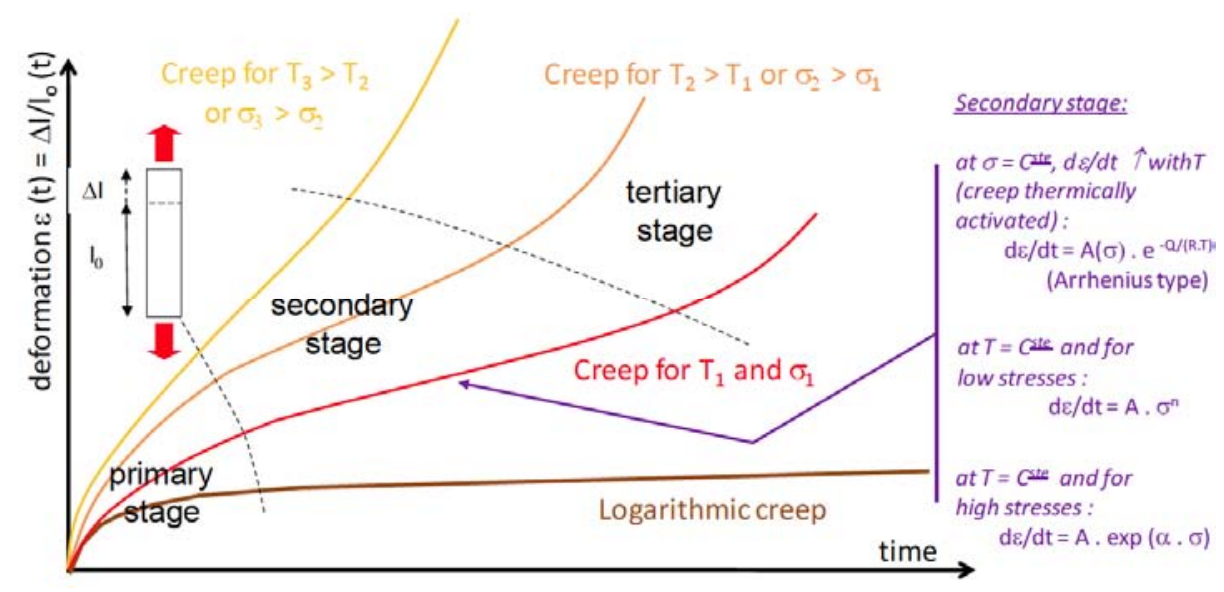

Figure 2: Qualitative examples of uniaxial creep curves with influence of stress and temperature; usual mathematical laws representing the dependence of the secondary creep deformation rate on stress and temperature.

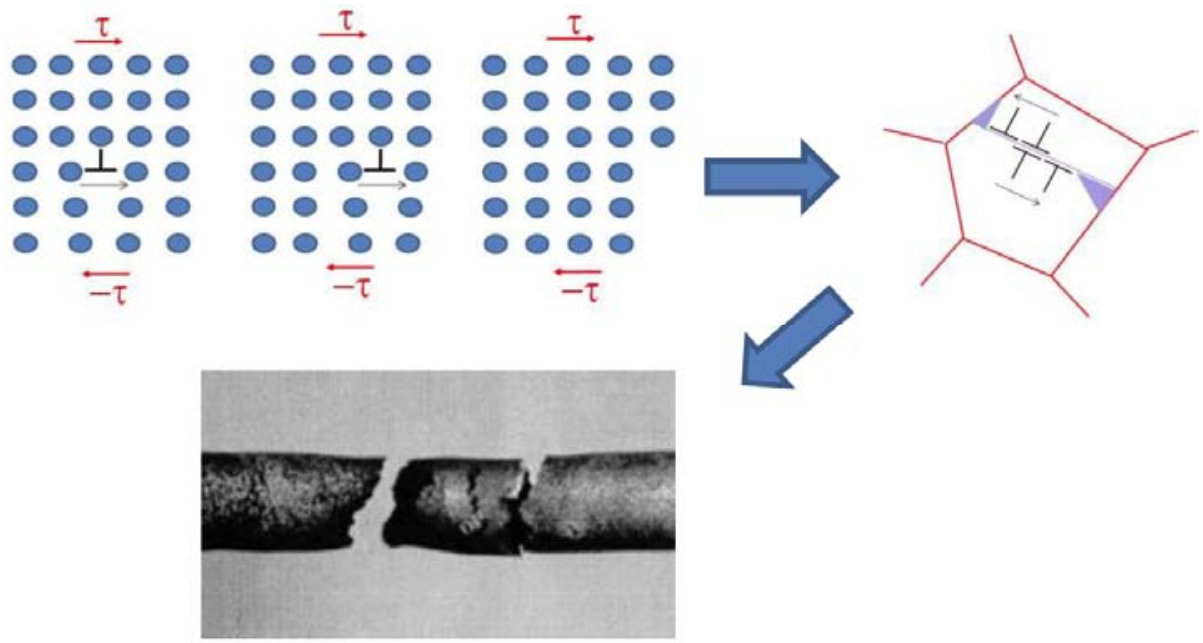

Figure 3: Movement of a "edge" dislocation, dislocations arriving in grain boundaries with initiation of micro-cracks after accumulation, intergrains propagation of cracks then rupture.

rotating blades and oxidation by gases is progressively replaced by corrosion by condensed salts. Although the local temperature is significantly lower than just after the combustion chamber the turbine blades situated there are at least so severely attacked. The different types of corrosion affecting the successive parts reached by the gases coming out of the combustion chamber, high temperature oxidation, high temperature hot corrosion and high low temperature hot corrosion, are shortly described in terms of qualitative rates in Figure 4, and in terms of mechanisms in Figure 5.

\section{CONSTITUTION OF THE SUPERALLOYS}

\section{Base Element}

The modern superalloys are much more complex than the initial $\{\mathrm{Ni}-30 \mathrm{Cr}\}$-based alloys. They are almost all still based on elements among nickel, cobalt and/or iron since these three elements are the ones which are able to lead, on the one hand, to the better combinations (Figure 6) of refractoriness and mechanical strength at high temperatures (at the service temperatures the alloys based on these elements are austenitic) and densities remaining compatibles with high rotation speeds (centrifugal stresses remaining low enough) and transport applications (from 1950 to 1990 the mass part of superalloys in an aeroengine has increased from $10 \%$ to $50 \%$ ). In contrast with the refractory alloys existing seventy years ago, the alloys have been progressively enriched with more and more other elements in higher and higher quantities.

\section{Atoms in Solid Solution: Hot Corrosion Resistance and Matrix Strengthening}

The first important alloying elements are aluminum and chromium. Aluminum allows a good resistance 

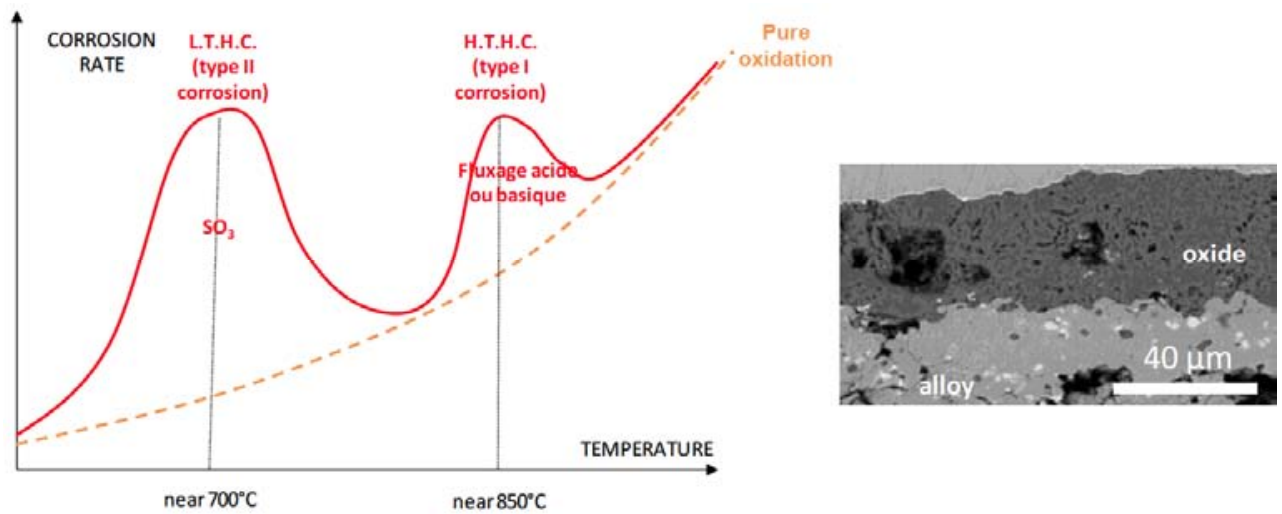

Figure 4: Relative corrosion rates versus temperature as is to say versus the location along the turbine axis; micrograph of a corroded component.

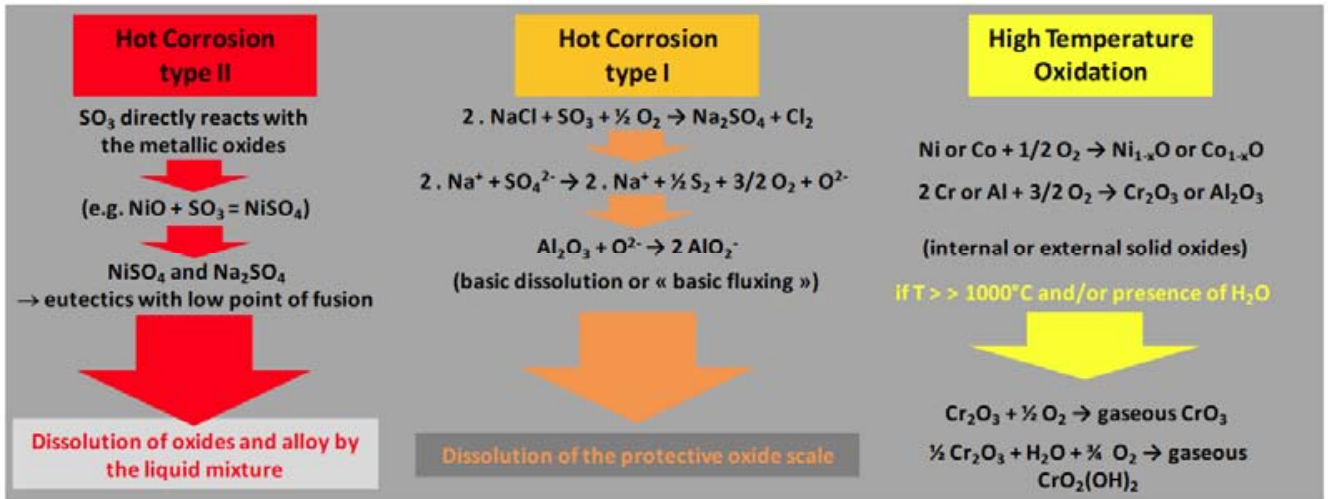

Figure 5: Reaction equations describing the mechanisms of three types of corrosion for aluminum-rich \{nickel and/or iron\}-based superalloys and chromium-rich nickel-based or cobalt-based superalloys.

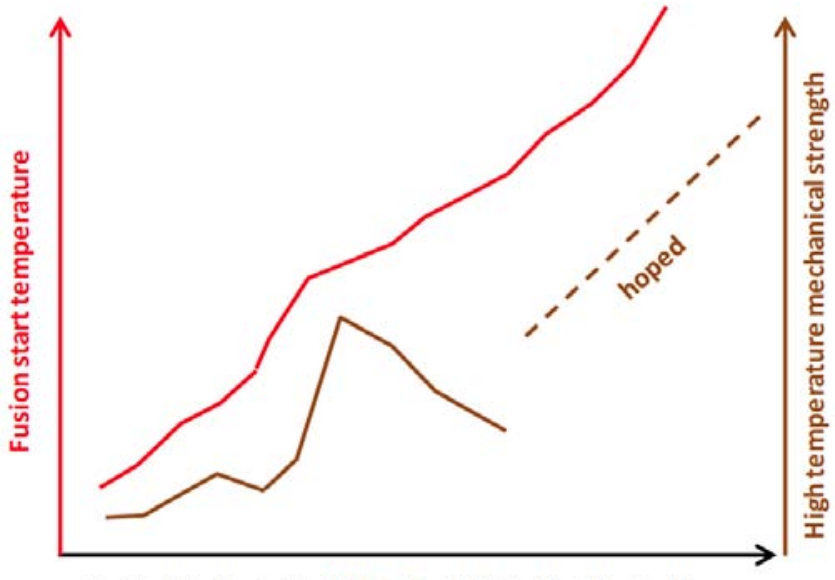

Sn Pb Mg Al Ag Cu Ni Co Fe V Ti Cr Nb Mo Ta W

Figure 6: Refractoriness and mechanical strength at high temperature versus the atomic number of the element.

against oxidation, even at very high temperatures. Indeed it forms by selective oxidation a continuous alumina scale $\left(\mathrm{Al}_{2} \mathrm{O}_{3}\right)$ which, as a stoichiometric oxide (without interstitial and vacancies in its crystalline network), limits significantly the diffusion of the ionic species involved in the oxidation phenomena and then acts as a protective barrier between the alloy and the oxidant gases. Chromium plays a similar role (Figure 7) by forming an external continuous chromia scale $\left(\mathrm{Cr}_{2} \mathrm{O}_{3}\right)$, which is a little less protective than alumina since chromia is not a fully stoichiometric oxide and, moreover, may be re-oxidized in volatile species (gaseous $\mathrm{CrO}_{3}$ ) when temperature is higher than $1000^{\circ} \mathrm{C}$. In contrast chromium is much more efficient in the resistance against sulfidation and corrosion by molten salts or glasses. If binary nickel alloys must contain at least $15 \mathrm{wt} . \% \mathrm{Al}$ to be alumina-forming or 20 wt. $\% \mathrm{Cr}$ to be chromia-forming (and $30 \mathrm{wt} \%$ for binary cobalt alloys), the minimal $\mathrm{Al}$ and/or $\mathrm{Cr}$ contents may be a little lower in more complex alloys which may contain $\mathrm{Al}$ and $\mathrm{Cr}$ simultaneously. Rare earth and other active elements $(\mathrm{Y}, \mathrm{La}, \mathrm{Ce}, \ldots)$ are sometimes also added to increase another time the oxidation resistance at high temperature.

Other of these alloying elements are heavy atoms (Mo, W, Ta, Re, ...) added to strengthen the alloys in solid solution, by locally distorting the matrix crystalline network by the presence of such big atoms, in order to install here a stress field able to obstruct the movement 

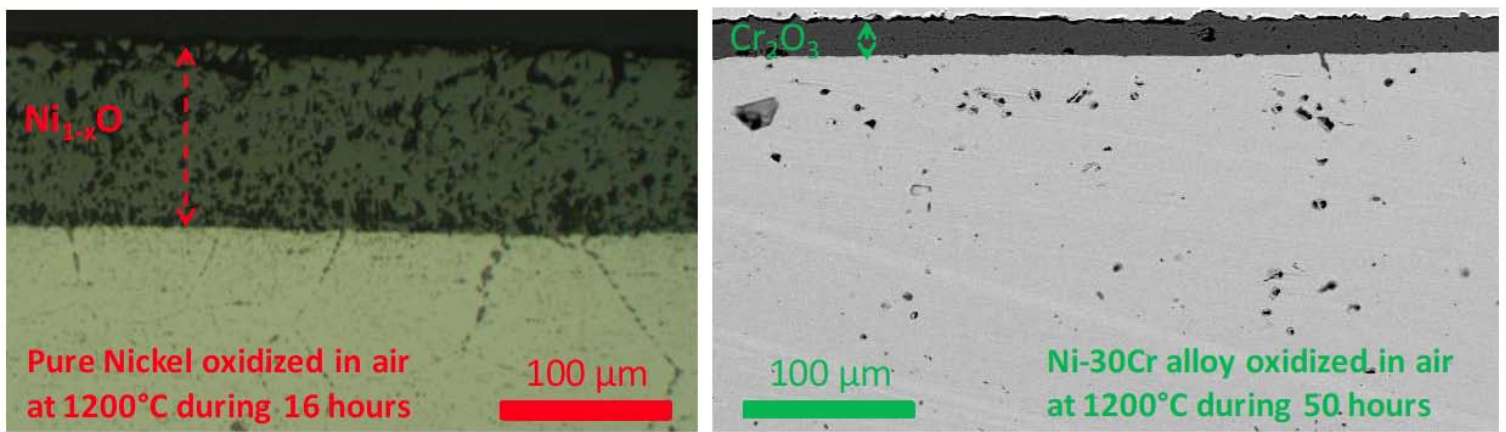

Figure 7: Illustration of the beneficial effect of 30 wt.\% of chromium in a nickel alloy (oxide scale thickness significantly thinner by comparison to pure nickel although the former was oxidized in air longer at the same temperature).

of dislocations (Figure 8). Cobalt atoms in nickel alloys and $\mathrm{Cr}$ atoms in nickel-based and in cobalt-based alloys may have also such an effect but more limited.

\section{Carbides: Matrix and Grain Boundaries Strengthening}

Carbides-forming atoms such as $\mathrm{Cr}, \mathrm{Ta}, \mathrm{W} \ldots$ again, may lead to carbides in presence of $C$ in other alloys. Such carbides may precipitate in the matrix during a specific heat-treatment (after casting for example) and the presence of such micrometric particles dispersed in matrix (secondary carbides, Figure 8) act as obstacles for dislocations, and then also decrease the creep deformation rates.

For carbon-containing alloys elaborated by foundry carbides can also appear as coarser carbides in the interdendritic spaces, at the end of solidification. The role of these primary carbides is also to slow down creep, but also to improve the interdendritic cohesion, and then delaying the tertiary creep. These carbides can be of different types: $\mathrm{Cr}_{7} \mathrm{C}_{3}$ and $(\mathrm{Cr}, \mathrm{W})_{23} \mathrm{C}_{6}$ for the chromium carbides, $\mathrm{TaC}$ and eventually $\mathrm{Ta}_{2} \mathrm{C}$ for the tantalum carbides, for example. The carbides compositions may be more complex: among the $\mathrm{MC}$ carbides one can find $(\mathrm{Ti}, \mathrm{Mo}) \mathrm{C}$ or $(\mathrm{Ti}, \mathrm{Nb}, \mathrm{W}) \mathrm{C}$ for instance. Other types of carbides can be also encountered, such as $\mathrm{M}_{6} \mathrm{C}$ carbides (e.g. $\left.\mathrm{Mo}_{3}(\mathrm{Ni}, \mathrm{Co})_{3} \mathrm{C}\right)$.

\section{Intermetallics: Matrix Strengthening}

Other particles, of the intermetallic type, may have prevent the dislocation movement in creep situation. The most important are the gamma prime $\left(\gamma^{\prime}\right)$ precipitated in aluminum-rich nickel-based and \{nickel, iron\}-based alloys during an adequate multi-stage heattreatment. These particles, often of the $\mathrm{Ni}_{3} \mathrm{Al}$ stoechiometry but the general formulation of which can be $(\mathrm{Ni}, \mathrm{Co}, \mathrm{Fe})_{3}(\mathrm{Al}, \mathrm{Ti}, \mathrm{Ta}, \mathrm{Nb})$ if such elements are present in the alloys, are Face Centred Cubic as the crystalline network of the austenitic alloys in which they are present. Furthermore they are coherent with matrix (Figure 8), in contrast with carbides which are not coherent with the austenitc matrix even for some of them which are also FCC (e.g. the TaC carbides). These intermetallic particles, the main reinforcement of the single crystals $\gamma / \gamma^{\prime}$ alloys which are the nickel-based alloys in which the highest volume fractions of $\gamma^{\prime}$ can be obtained, have an average size of about $1 \mu \mathrm{m}$ and are all coherent with matrix. Among the other elements present in these alloys some of them stay predominantly present in matrix $(\mathrm{Cr}, \mathrm{Co}, \mathrm{Fe}, \mathrm{Mo}, \mathrm{W}, \mathrm{Re}$ ...) while others are much present in the $\gamma^{\prime}$ precipitates than in matrix (Al, Ti, Ta, V, Hf, ...). Depending on the respective chemical compositions of matrix and intermetallics, and then on the parametric difference between them $-\delta=2$. $\left(a_{i}-a_{i}\right) /\left(a_{i}+a_{i}\right)$ - the shape of the particles varies. The smallest $\gamma^{\prime}$ particles are spherical and the biggest ones are cuboïdal for high parametric mismatches, and all are spherical without dependence on the precipitate size when the parametric mismatch is very low.

Other intermetallic particles may be obtained in superalloys also for improving their mechanical behavior at high temperature. Gamma second $\left(\gamma^{\prime \prime}\right)$ precipitates can be present in nickel/iron-based $\mathrm{Nb}$ containing alloys. The composition of these quadratic intermetallics coherent with matrix is $\mathrm{Ni}_{3} \mathrm{Nb}$ or more generally $(\mathrm{Ni}, \mathrm{Fe})_{3}(\mathrm{Nb}, \mathrm{Al})$. The intermetallic $\mathrm{Co}_{3}(\mathrm{Al}, \mathrm{Ti})$ may be encountered in rare cobalt-based alloys.

\section{Other Strengthening Particles}

Boron, element which can be added to give more ductility to the grain boundaries for contents ranging from 50 to $500 \mathrm{ppm}$, may lead to the precipitation of borides $\mathrm{M}_{3} \mathrm{~B}_{2}$ - e.g. ( $\left.\mathrm{Mo}, \mathrm{Ti}, \mathrm{Cr}, \mathrm{Ni}, \mathrm{Co}\right)_{3} \mathrm{~B}_{2}$ - in the same locations. O.D.S. (oxide dispersion strengthened) 


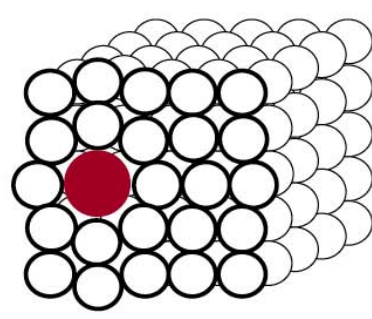

Substitutional big atom in solid solution (e.g. W in a $\{\mathrm{Fe}, \mathrm{Ni}\}$-based matrix)

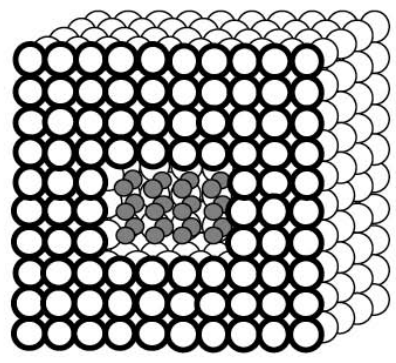

Crystalline precipitate coherent with matrix (e.g. $\boldsymbol{y}^{\prime}$ in a Ni-based matrix)

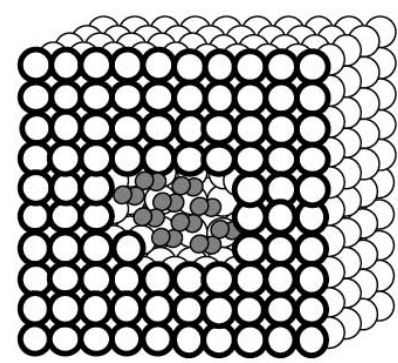

Crystalline

precipitate coherent

with matrix (e.g.

secondary carbide in

a Co-based matrix)

Figure 8: Simplified scheme of the crystalline network distortion by atoms in solid solution and by coherent or not-coherent precipitates.

superalloys contain dispersed oxides of 200-400 Angströms which are the most often $\mathrm{Y}_{2} \mathrm{O}_{3}$ (yttria), but wich can be also $\mathrm{ThO}_{2}, \mathrm{Al}_{2} \mathrm{O}_{3}$ or others. Such nanometric particles are very efficient as obstacles for dislocations.

\section{Metallurgical Instabilities}

In service at constant temperature or not, the microstructure may evolve to the thermodynamic stable states corresponding to their chemical composition. Some of the strengthening particles may transform into new phases or simply change for new volume fractions or morphologies. This is the case of carbides, with for example $\mathrm{M}_{7} \mathrm{C}_{3}$ evolving into $\mathrm{M}_{23} \mathrm{C}_{6}$, or TaC carbides becoming fractioned at very high temperatures. The $\gamma^{\prime}$ particles may also become "rafted" (elongated) under the double action of high temperature exposure and of application of tensile stress, or while the $\gamma$ " reinforcing some alloys may degenerate into the harmful orthorhombic $\mathrm{Ni}_{3} \mathrm{Nb} \delta$ phase.

In another way, for the same reasons, in service but also possibly during the elaboration of the alloys (notably heat-treatments), due to the fact that the superalloys have been more and more enriched in several heavy elements simultaneously to achieve higher and higher properties at high temperature, new phases may appear sooner or later. A first example is the $\eta$ phase, a hexagonal $\mathrm{Ni}_{3}(\mathrm{Ti}, \mathrm{Ta}, \mathrm{Nb})$ intermetallic which may appear in grain boundaries with Widmanstätten form in nickel/iron-based superalloys displaying high contents in titanium, tantalum or niobium. But the more frequent phases to appear and weaken the alloys are the "Topologically Closed Packed" phases (TCP), which are brittle and deteriorate the mechanical properties at all temperatures. They precipitate from the matrix saturated in $\mathrm{Cr}$, Co, $\mathrm{W}$, Mo or Re, or from some intergranular carbides. These TCP phases are: the quadratic centred sigma phase $(\sigma$, example of composition: $\left.\mathrm{Co}_{2} \mathrm{Mo}_{3}, \mathrm{CrFe}, \mathrm{CoCr}, \mathrm{Cr}_{8} \mathrm{Ni}_{5} \mathrm{~W}, ..\right)$, the rhomboedric mu phase ( $\mu$, general composition: (Co, $\left.\mathrm{Fe}, \mathrm{Ni})_{7}(\mathrm{Mo}, \mathrm{W}, \mathrm{Cr})_{6}\right)$ and the hexagonal or face centred cubic Laves phases (general composition: $(\mathrm{Fe}, \mathrm{Cr}, \mathrm{Co}$, $\mathrm{Mn}, \mathrm{Si})_{2}(\mathrm{Mo}, \mathrm{Ti}, \mathrm{Ta}, \mathrm{Nb})$, examples: $\mathrm{Co}_{2} \mathrm{Mo}, \mathrm{Co}_{2} \mathrm{Ta}$, $\left.\mathrm{Cr}_{2} \mathrm{Ta}, \ldots\right)$.

\section{ELABORATION OF THE SUPERALLOYS}

\section{Advanced Foundry, Forging}

In contrast with the first refractory alloys which did not contain very oxidable elements this allowing elaborating them in air, modern superalloys must be elaborated by vacuum induction melting (VIM) or in gaseous inert atmosphere (vacuum of e.g. $10^{-5} \mathrm{~atm}$ or better, $\operatorname{argon} . .$.$) to avoid oxidation and too high$ concentrations of undesired elements (e.g. less than 10 $\mathrm{ppm}$ of nitrogen, less than $1 \mathrm{ppm}$ of hydrogen). Induction heating (50 to $200 \mathrm{MHz}$ ), electric arc or electrons bombing allow reaching the liquid state before eventually adding the most oxidable elements $(\mathrm{Ti}, \mathrm{Al})$ or the small quantities of active elements $(\mathrm{Hf} . .$. and pouring the molten alloy. After solidification in cylindrical ingots the alloys can be melted again in vacuum arc remelting (VAR) or electroslag remelting (ESR) operations. If the two processes aim to chemically homogenize the alloy by suppressing the axial segregations issued from the primary solidification, the VAR operation allows additionally purifying the melt in the rare gaseous species still trapped in the alloy while the ESR operation allows collecting the small oxides which may appear during the primary foundry operation. These small oxides are trapped by aggregation with the slag. 


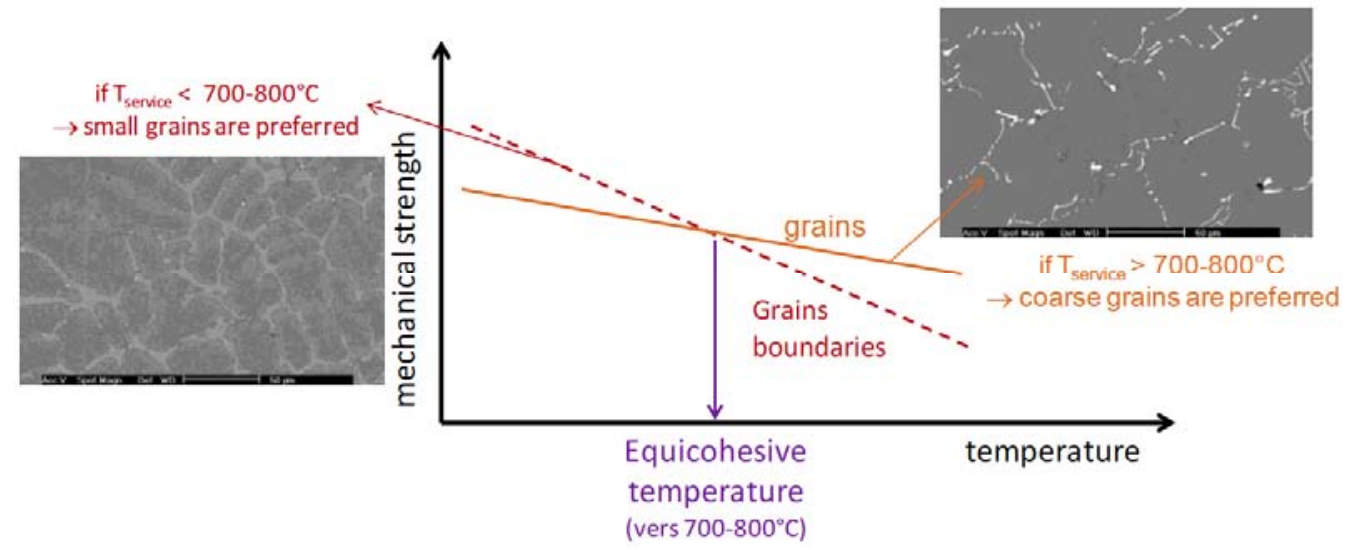

Figure 9: Qualitative comparison of the strength of grains and grains boundaries versus temperature.

The foundry way leads to polycrystalline equiaxed alloys characterized by a grain size, and therefore a density of grain boundaries, which both vary with the solidification rate. If small grains are preferred to achieve good mechanical properties at low or medium temperatures, coarser grains are in contrast beneficial to the creep resistance at high temperature. For a given cast alloy there is a equicohesive transition temperature (generally close between $700^{\circ} \mathrm{C}$ and $800^{\circ} \mathrm{C}$ for cast superalloys) at which the resistance of grains and the resistance of grain boundaries are supposed to be equivalent (Figure $\mathbf{9}$ ).

Thus, microstructurally coarser cast superalloys are preferred to use at very high temperature under stresses. It is furthermore possible to limit the weakening effect of the grain boundaries at high temperature service by better orientating them or simply suppressing them. Directional solidification occurring in an elongated crucible withdrawn from a hot zone along a well oriented thermal gradient may lead to directionally solidified alloys able to show very high mechanical properties in the obtained microstructural orientation. If a grain selector is placed between the solidification start point and the main volume to solidify it is possible to obtain only one grain. The single crystal alloys obtained by this way present especially high mechanical properties (but anisotropic) in the growth direction, as well as a high refractoriness due to the absence of elements usually used to reinforce grain boundaries absent in such single crystal alloys, among them carbon (and some carbide-former elements) and boron, for example. A typical use of single crystal is for turbine blades working in the hottest parts of an aeroengine.

Even if some foundry superalloys can be used in their as-cast condition, one or several heat-treaments are generally applied. They aim first to chemically homogenize the alloys and/or to suppress the eventual stresses appeared during cooling (stress-releaving). Second, they induce the precipitation in the alloys of strengthening particles (secondary carbides, gamma prime ... ) with the adequate size, density and homogeneity. The most often such hardening heattreatments are composed of a rather short (e.g. a few hours) solution treating part at high temperature (e.g. $1150^{\circ} \mathrm{C}$ ) to dissolve the unwanted particles appeared during solidification and homogenize the chemical composition (to prepare the best conditions for the following part), and a precipitation part performed at lower temperature (e.g. $950^{\circ} \mathrm{C}$ ) for a longer time (e.g. a few tens hours).

After conventional casting the ingots may be also forged for obtaining grains with decreased size and achieving hardening, to better mechanical performances at medium temperatures. Turbine disks represent a typical use of such forged alloys. Subsequent annealing or recrystallization heattreatments may also be performed on the forged pieces.

\section{Powder Metallurgy, O.D.S. Alloys}

Powder metallurgy is one of the elaboration ways preferred to foundry to fabricate alloys based on very refractory metallic elements, as $\mathrm{Nb}, \mathrm{Mo}, \mathrm{W}$ or $\mathrm{Ta}$, the fusion points of which range from 2500 to more than $3000^{\circ} \mathrm{C}$ ). But this synthesis way may also be considered to produce \{fine grained\}- or \{segregation free\}-superalloys from pure metal or pre-alloyed powders (elaborated from liquid by vacuum or argon atomization, rotating electrodes, ...), with granulometry ranging from several tens to several hundreds of micrometers. Sintering may be performed on the pre- 
Table 1: Examples of Cast and Wrought Superalloys with their Chemical Compositions (Contents in wt.\%)

\begin{tabular}{|c|c|c|c|c|c|c|c|c|c|}
\hline Co or $\mathrm{Ni}$ & $\mathrm{Fe}$ & Al & $\mathrm{Cr}$ & C & $\mathrm{Ti}$ & $\mathrm{Ta}$ & Mo & $\mathbf{w}$ & other \\
\hline \multicolumn{10}{|c|}{ Cast nickel-based superalloy: Inconel 100} \\
\hline $15 \mathrm{Co}$ & l & 5.5 & 10 & 0.18 & 5 & l & 3 & l & $\begin{array}{c}0.01 \mathrm{~B} \\
0.06 \mathrm{Zr} \\
1 \mathrm{~V}\end{array}$ \\
\hline \multicolumn{10}{|c|}{ Directionally solidified nickel-based superalloy: Wax-20 } \\
\hline l & l & 6.5 & l & 0.20 & & & l & 20 & $1.5 \mathrm{Zr}$ \\
\hline \multicolumn{10}{|c|}{ Single crystal nickel-based superalloy: CMSX-6 } \\
\hline $5 \mathrm{Co}$ & I & 4.8 & 10 & I & 4.7 & 2 & 3 & I & l \\
\hline \multicolumn{10}{|c|}{ Cast cobalt-based superalloy: Mar-M 509} \\
\hline $10 \mathrm{Ni}$ & l & l & 23.5 & 0.6 & 0.2 & 3.5 & l & 7 & $0.5 \mathrm{Zr}$ \\
\hline \multicolumn{10}{|c|}{ Wrought solid solution cobalt-based superalloy: Haynes 188} \\
\hline $22 \mathrm{Ni}$ & I & l & 22 & 0.10 & l & I & l & 14.5 & $0.9 \mathrm{La}$ \\
\hline \multicolumn{10}{|c|}{ Wrought precipitation-hardening iron-nickel-based superalloy: Pyromet CTX-1 } \\
\hline $38 \mathrm{Ni} 16 \mathrm{Co}$ & 39 & 1 & l & 0.03 & 1.7 & I & 0.1 & I & $3 \mathrm{Nb}$ \\
\hline \multicolumn{10}{|c|}{ Iron-based O.D.S. superalloy: Incoloy MA 956} \\
\hline I & Bal. & 4.5 & 20 & l & 0.6 & l & I & l & $0.5 \mathrm{Y} 2 \mathrm{O} 3$ \\
\hline
\end{tabular}

consolidated powder mixtures by exposing the green pieces to high temperature with or without application of a mechanical pressure, uniaxial or isostatic. Before sintering under pressure encapsulation and vacuum are necessary in case of the existence of open porosities.

Powder metallurgy also allows the homogeneous incorporation of micrometric or nanometric particles as the oxides (e.g. $\mathrm{Y}_{2} \mathrm{O}_{3}$ or $\mathrm{ThO}_{2}$ ) allowing both mechanical strengthening (very good efficiency against the dislocation movement) and high oxidation resistance (pinning of the protective external oxide scales on the alloy surface, avoiding spallation under growth compressive stresses or in thermal cycling). Powder metallurgy after mechanical alloying of powders' mixtures including nano-particles of oxides, combined with subsequent successive different phases of hot working and multi-stage heat-treaments leading to anomalous growth of pre-selected grains, lead to special polycrystalline and anisotropic microstructures composed of very coarse grains with size of several tens centimeters, columnar (extruded bars) or with form of more or less irregular disks (laminated sheets). These O.D.S. (Oxide Dispersion Strengthened) superalloys, which are the most often based on nickel or on iron, display exceptional mechanical properties remaining good even at temperatures only a few degrees lower than their solidus temperature, as well as good resistance against high temperature isothermal or cyclic oxidation.

\section{Coatings}

The resistance of the pieces against hot gases may be improved by the creation of surfaces designed to resist high temperature oxidation, by using different techniques: electrolytic deposition, CVD and PVD techniques, plasma projection). It is for example to deposit elements and form surface alloys with compositions especially devoted to oxidation resistance

Table 2: Examples of Oxide Dispersion Strengthened Superalloys with their Chemical Compositions (Contents in wt.\%)

\begin{tabular}{|c|c|c|c|c|c|c|}
\hline $\mathrm{Ni}$ & $\mathrm{Fe}$ & Al & $\mathrm{Cr}$ & $\mathrm{Ti}$ & C & $\mathbf{Y}_{2} \mathbf{O}_{3}$ \\
\hline \multicolumn{7}{|c|}{ Nickel-based O.D.S. superalloy: Incoloy MA 754} \\
\hline Bal. & l & 0.3 & 20 & 0.5 & 0.05 & 0.6 \\
\hline \multicolumn{7}{|c|}{ Iron-based O.D.S. superalloy: Plansee PM 2000} \\
\hline l & Bal. & 5.5 & 19 & 0.5 & I & 0.5 \\
\hline
\end{tabular}




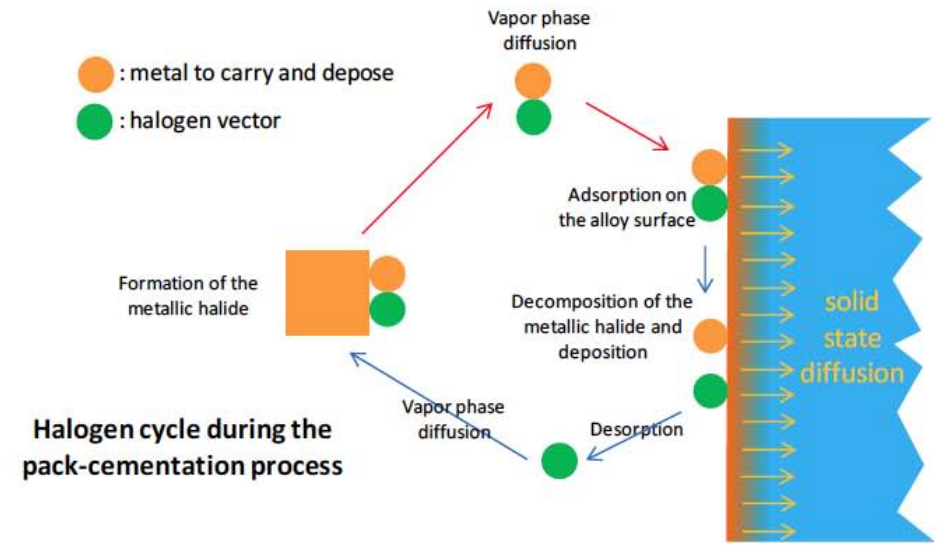

Figure 10: Pack-cementation to lay down $\mathrm{Al}, \mathrm{Cr}$ or Si on the alloy surface.

without any mechanical consideration, as $(\mathrm{Ni}$, Co)CrAIY(Ta) coatings. Its is possible to directly enrich the surface of the superalloys in chromium, aluminum and/or silicon by deposition or co-deposition using the CVD pack-cementation technique illustrated in Figure 10. A MCrAlY coating previously formed can thereafter act as bon coat for the adhesion of a columnarstructured thermal barrier coating (TBC) to thermally isolate the superalloy from too hot gases.

\section{TESTING THE PROPERTIES OF SUPERALLOYS}

\section{Mechanical Tests}

The classical mechanical tests can be performed to assess the properties of superalloys at high temperature. Specific apparatus must be used in addition to the usual machine tests, as resistive (Figure 11), inductive (coil around the main part of the sample) or image furnace and grips and extensometers adapted to high temperatures. The atmosphere of test can be air or also inert gas to avoid the influence of oxidation to the mechanical behavior of the studied superalloy.

\section{Oxidation Tests}

Isothermal exposures to hot air or to other hot gases in a simple resistive muffle or tubular sample may be performed over long times on samples, with subsequent measurement of the mass difference between before and after oxidation. But thermogravimetric tests using a thermo-balance (Figure 12) may give useful information about the kinetic progress of the oxidation phenomenon, by measuring the mass of the sample all along the exposure to oxidant gas (mass variation caused by oxygen joining the most oxidable elements of the alloy two form oxides). The most frequent behavior of an alloy knowing first transient oxidation and thereafter an oxidation rate governed by the diffusion of ionic species through a continuous oxide layer is a linear kinetic $\left(\Delta \mathrm{m} / \mathrm{S}=\mathrm{K}_{1} . \mathrm{t}\right)$ followed by a parabolic kinetic $(\Delta \mathrm{m} / \mathrm{S}=$ $\left.\left(2 \mathrm{~K}_{\mathrm{p}} \cdot \mathrm{t}\right)^{1 / 2}\right)$ the linear $\left(\mathrm{K}_{\mathrm{l}}\right)$ and parabolic $\left(\mathrm{K}_{\mathrm{p}}\right)$ constants [5] of which can be easily determined from the mass gain measurements. In some cases (e.g. chromiaforming alloys subjected to air at more than $1000^{\circ} \mathrm{C}$ or presence of water vapor in the oxidant gas) another linear constant needs to be taken into account: a volatilization constant $\mathrm{K}_{\mathrm{v}}$. Indeed the accuracy of determination of the $\mathrm{Kp}$ constant requires to know the chromia volatilization (Figure 5) rate. Approached values of $\mathrm{Kv}$ can be obtained by treating the thermogravimetry results according to several methods, e.g. as described in [6] or [7].

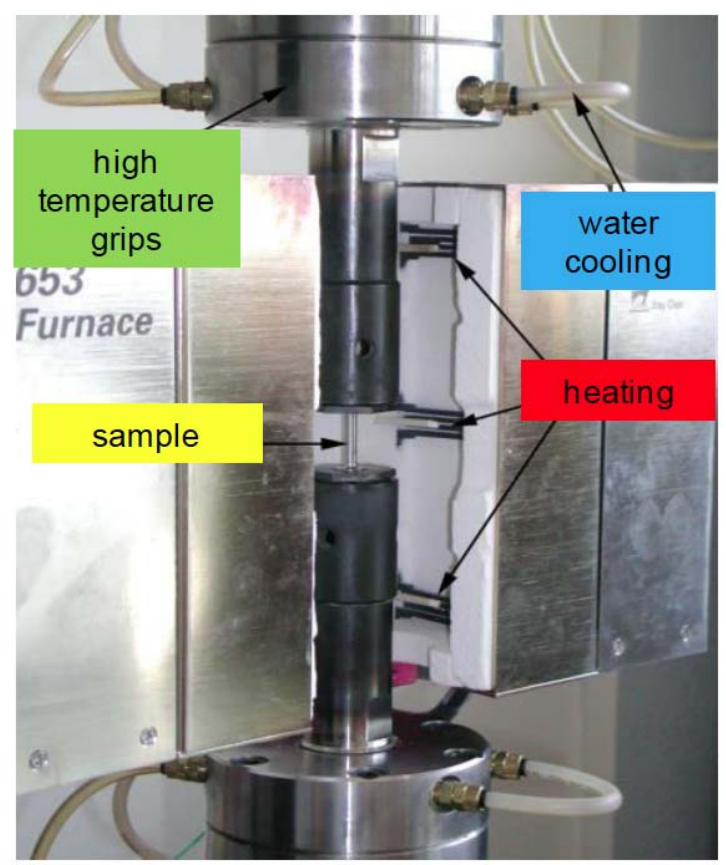

Figure 11: Sample and grips in a resistive furnace for tensile test at high temperature. 

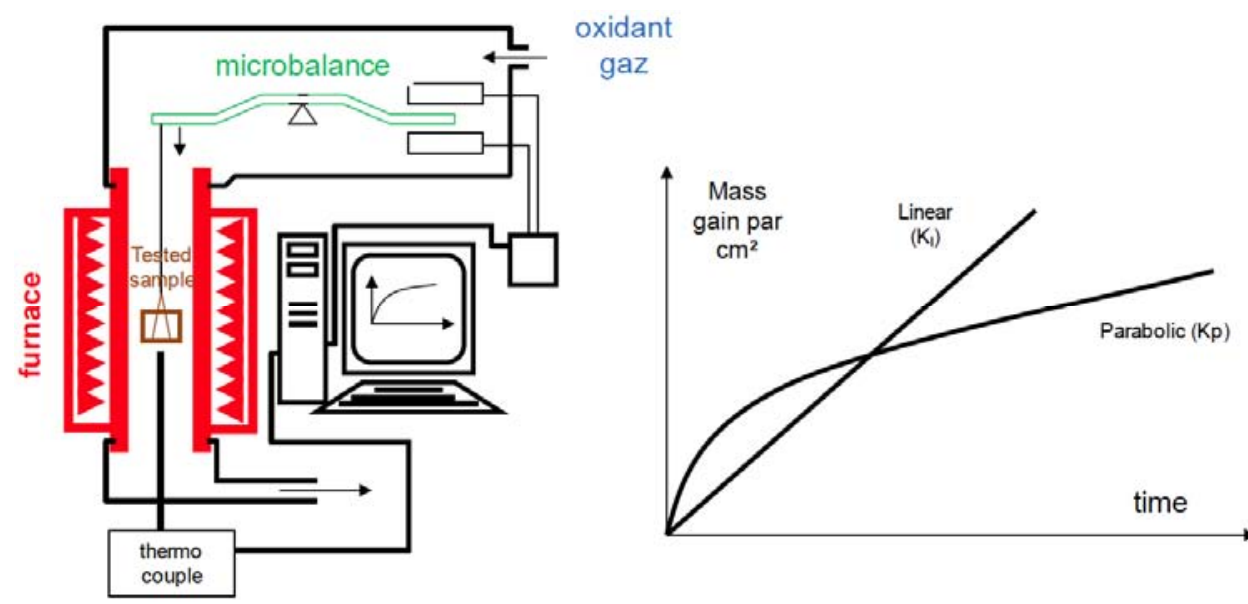

Figure 12: Scheme of a thermobalance which is among the most usual apparatus (left) allowing the mass gain kinetic and two of the main types of high temperature oxidation kinetic (right).

\section{Corrosion Tests}

Corrosion runs of superalloys by molten salts or glasses can be achieved simply by immersion in the studied molten substance for the selected temperatures and duration. The kinetic of the corrosion phenomena can be also studied by measuring the electrochemical quantities as corrosion potential, polarization resistances, corrosion current, ... [8] by the same electrochemical methods and apparatus used to qualify aqueous corrosion of metals (three-electrodes cell, potentiostat, ... ). The main differences are the vessel (e.g. in a platinum alloy here), the constitution of the electrodes: the one giving the potential reference (e.g. zirconia here), the counter electrode (e.g. platinum here), the working electrode (superalloy). The electrodes are linked to the potentiostat present outside the furnace by platinum wires sheathed by alumina for example (Figure 13).

At the end of the test - simple immersion or electrochemical study - the sample can be withdrawn from the bath, sheathed to avoid, during the cooling, the loss of the corrosion products with the solidified substance remaining on the sample, and then metallographically prepared for macro and microexamination.

\section{METALLOGRAPHY EXAMINATIONS}

After each step of their elaboration, at the end of their service period or after the preceding laboratory tests (including the corrosion ones) the samples of superalloys can be prepared as other metallic samples: cutting, embedding in hot resin or \{cold resin+hardener\}-mixture, polishing (e.g. grid papers from 80 grit to 2400 grit under water and textile enriched in micrometric hard particles until reaching a mirror-like surface state. In the case of the oxidized samples, whatever the test of oxidation by gases (furnace or thermobalance) the oxidized superalloys samples may be characterized by post-mortem examinations. This can be initially done by characterizing the outer surface of the external oxide
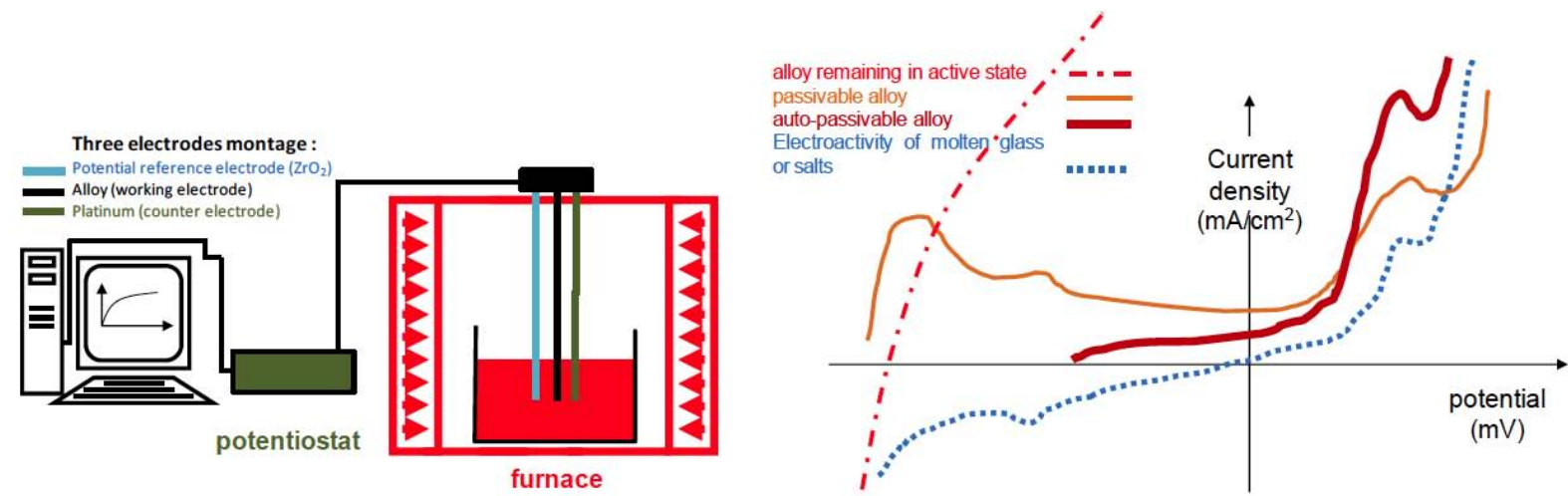

Figure 13: Scheme of an electrochemical apparatus allowing specifying the hot corrosion of superalloy in a molten substance (left); schematic examples of polarization curves which can be obtained (rignt). 
scales by Electron microscopy, X-Ray diffraction, ... before preparing cross-sections. For this later preparation, it can be useful to protect the scales before cutting. For that a procedure which allows the lowest loss of information is doing on them first a cathodic pulverization of metal (gold for example) to allow the external oxide scales becoming electrically conductive, then depositing a nickel coating by cathodic polarization in a \{nickel cations\}-containing Watt's bath heated at about $50^{\circ} \mathrm{C}$ under about $15 \mathrm{~mA}$ per $\mathrm{cm}^{2}$ of sample surface. After these preliminary preparations, cutting (and thereafter polishing) can be performed without damage for the oxides scale.

\section{Optical Microscopy}

The embedded and polished samples can be directly examined with optical microscope to observe the cross-sections of the oxide scales on the oxidized samples or parts of industrial pieces (degree of porosity, tendency to unsticking, thickness) and also the microstructure in some cases (presence of hard particles in relief over the softer matrix). But to greatly improve contrast of the already visible particles or to color and reveal the other ones, etching can be done.

Examples of microstructures of two carbidesstrengthened cast superalloys after ecthing are given in Figure 14.

\section{Electron Microscopy}

The complex chemical compositions of superalloys, involving simultaneously low atoms, medium atoms and heavy atoms often facilitate their microstructure examination by electron microscopy, notably using Scanning Electron Microscope (SEM) in Back Scattered Electrons (BSE) mode which exploit the difference of average atomic number of the phases to give a good contrast between them (Figure 15). Typically, chromium carbides appear in black or grey depending on their stoichiometry, oxides in dark $\left(\mathrm{Al}_{2} \mathrm{O}_{3}\right.$, $\left.\mathrm{Cr}_{2} \mathrm{O}_{3}\right)$ or white $\left(\mathrm{Ta}_{2} \mathrm{O}_{5}\right.$ or $\left.\mathrm{CrTaO}_{4}\right), \mathrm{MC}$ carbides in white $(\mathrm{TaC}), \ldots$ by comparison with a greey Ni-based or Co-based matrix. The Secondary Electron mode (SE) gives a lower contrast of composition but reveals the surface relief: microstructure after etching (e.g. $\gamma$ ' precipitates), porosities, micro-cracks, ... If SEM is limited to about $\times 50,000$, Field Emission Gun Scanning Electron Microscopes and Transmission Electron Microscopes (TEM) observing extra-thin samples may lead to much higher magnifications, which allow observing dislocations. Further, atomic network can be revealed by High Resolution Transmission Electron Microscopes (HRTEM). The Energy Dispersive Spectrometry (EDS) apparatus often equipping the SEM allows pinpoint semi-quantitative analysis to chemically specify the observed phases, matrix as well as precipitates (if these ones are not too small). X-maps can be also acquired for a general identification of all the phases present in the observed area (Figure 16).

\section{Microprobe}

More quantitative results concerning the chemical composition of the different phases present in the microstructure can be obtained by Wavelength Dispersive Spectrometry (WDS) using a microprobe,

Table 3: Examples of Etchants Used for the Microstructure Examination of Superalloys

\begin{tabular}{|c|c|}
\hline \multicolumn{2}{|c|}{ All alloys } \\
\hline $\begin{array}{l}15 \mathrm{~g}\left(\mathrm{NH}_{4}\right)_{2} \mathrm{~S}_{2} \mathrm{O}_{8}, 75 \mathrm{ml} \text { distilled water, } 250 \mathrm{~g} \mathrm{FeCl}_{3}, 100 \mathrm{ml} \mathrm{HCl} \text { then } \\
\text { add } 30 \mathrm{ml} \mathrm{HNO}_{3} \\
\text { Immersion } 1 / 2 \text { to } 2 \text { minutes at room temperature }\end{array}$ & $\begin{array}{l}\text { To observe the gamma prime precipitates of the } \gamma / \gamma^{\prime} \text { superalloys } \\
\text { (they appear in relief) }\end{array}$ \\
\hline \multicolumn{2}{|c|}{ Nickel-based superalloys } \\
\hline $\begin{array}{c}3 \text { volumes of glycerol, } 2 \text { to } 3 \text { volumes of } \mathrm{HCl}, 1 \text { volume of } \mathrm{HNO}_{3} \\
\text { To mix at room temperature and use immediately: immersion for } 5 \text { to } \\
60 \text { seconds (Glyceregia) }\end{array}$ & $\begin{array}{l}\text { To observe the gamma prime precipitates of the } \gamma / \gamma^{\prime} \text { superalloys } \\
\text { (they appear in relief) }\end{array}$ \\
\hline $\begin{array}{l}\qquad 20 \mathrm{ml} \mathrm{HNO}, 60 \mathrm{ml} \mathrm{HCl} \\
\text { To use immediately (Aqua regia) }\end{array}$ & Reveals grains boundaries, carbides and attacks the sigma phase \\
\hline \multicolumn{2}{|c|}{ Cobalt-based superalloys } \\
\hline $\begin{array}{l}10 \mathrm{~g} \mathrm{~K}_{3} \mathrm{Fe}(\mathrm{CN})_{6}, 10 \mathrm{~g} \mathrm{KOH}, 100 \mathrm{~cm}^{3} \mathrm{H}_{2} \mathrm{O} \\
\text { Immersion during a few seconds at room temperature (Murakami) }\end{array}$ & Reveals carbides $(\mathrm{TaC}, \ldots)$ \\
\hline $\begin{array}{c}4 \mathrm{~g} \mathrm{KMnO}_{4}, 4 \mathrm{~g} \mathrm{NaOH}, 100 \mathrm{~cm}^{3} \mathrm{H}_{2} \mathrm{O} \\
\text { Immersion during a few tens seconds at room temperature } \\
\text { (Groesbeck) }\end{array}$ & Reveals carbides $\left(\mathrm{M}_{23} \mathrm{C}_{6} \ldots\right)$ \\
\hline
\end{tabular}



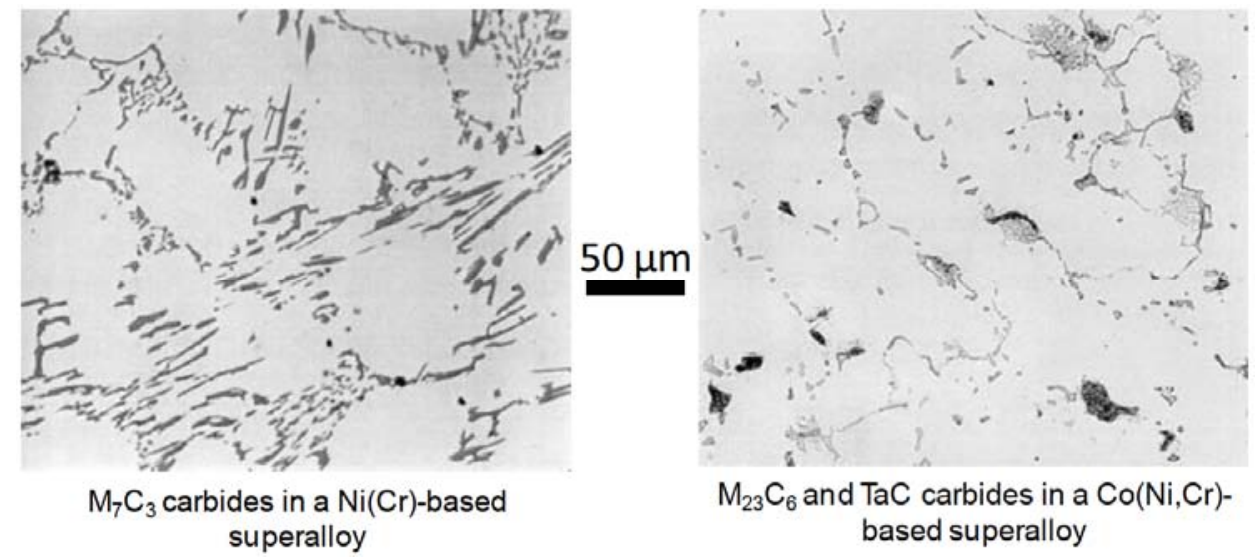

Figure 14: Example of microstructures attacked with the Groesbeck etchant for revealing carbides before optical microscopy examination.

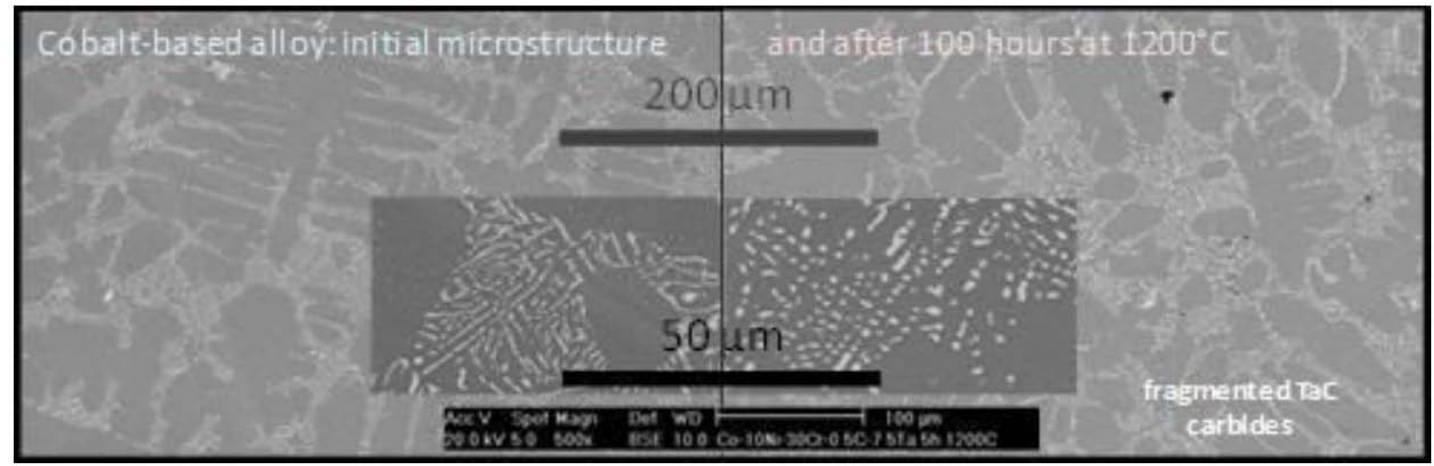

Figure 15: Observation of the fragmentation of the eutectic TaC carbides (white) of a cast cobalt-based superalloy after long service at very high temperature, using a SEM in BSE mode.

except for the two light elements. Measurements can be of the pinpoint type, maps or profiles. In the later case microprobe allow specifying the distribution and concentration gradients respectively across the microstructure (e.g. to study the chemical homogeneity of the bulk) or across the sub-surface affected by high temperature oxidation or corrosion (Figure 17).

\section{X-Ray Diffraction}

Polished microstructures can also be subjected to $X$-Ray diffraction in order to complete the identification of the existing phases, by collecting diffracted rays and indexing the obtained diffraction peaks (angles, intensity), and then précising the crystalline networks of the present phases. Diffractometers can be also used on the external oxide scales (Figure 18) to specify the different types of oxides formed over the sample of superalloys after oxidation test. Further, some diffractometers allow analyzing in situ the oxides continuously during their nucleation and growth on a heated sample of alloy in a gaseous atmosphere, air without or with water vapor for example.

\section{Other Analysis Techniques}

To finish this not exhaustive list of metallography means one can also cite the X-Ray Photoelectron Microscopy technique (XPS) which allows analyzing the chemical composition of extreme surfaces (oxidation scales) coupled with an erosion by a argon beam to analyze in an increasing depth to realize concentration profiles, secondary ion mass spectrometry (SIMS) which allows the elemental and isotopic analysis on surface by pulverizing and ionizing a part of it to allow its analysis by and electron backscatter diffraction (EBSD) which may bring maps of distribution, orientation and sizes of grains. Such technique is for example used to localize the presence of the ${ }^{18} \mathrm{O}$ isotope of oxygen in an oxide scale grown by high temperature oxidation of a superalloy exposed to a mix or $\mathrm{N}_{2}$ and ${ }^{18} \mathrm{O}_{2}$ during only a part of the oxidation test. This can show if the diffusion through the oxide scale was anionic or cationic [9].

\section{CONCLUSION}

The superalloys, which can be based on several elements (only the ones based on nickel, iron or cobalt 

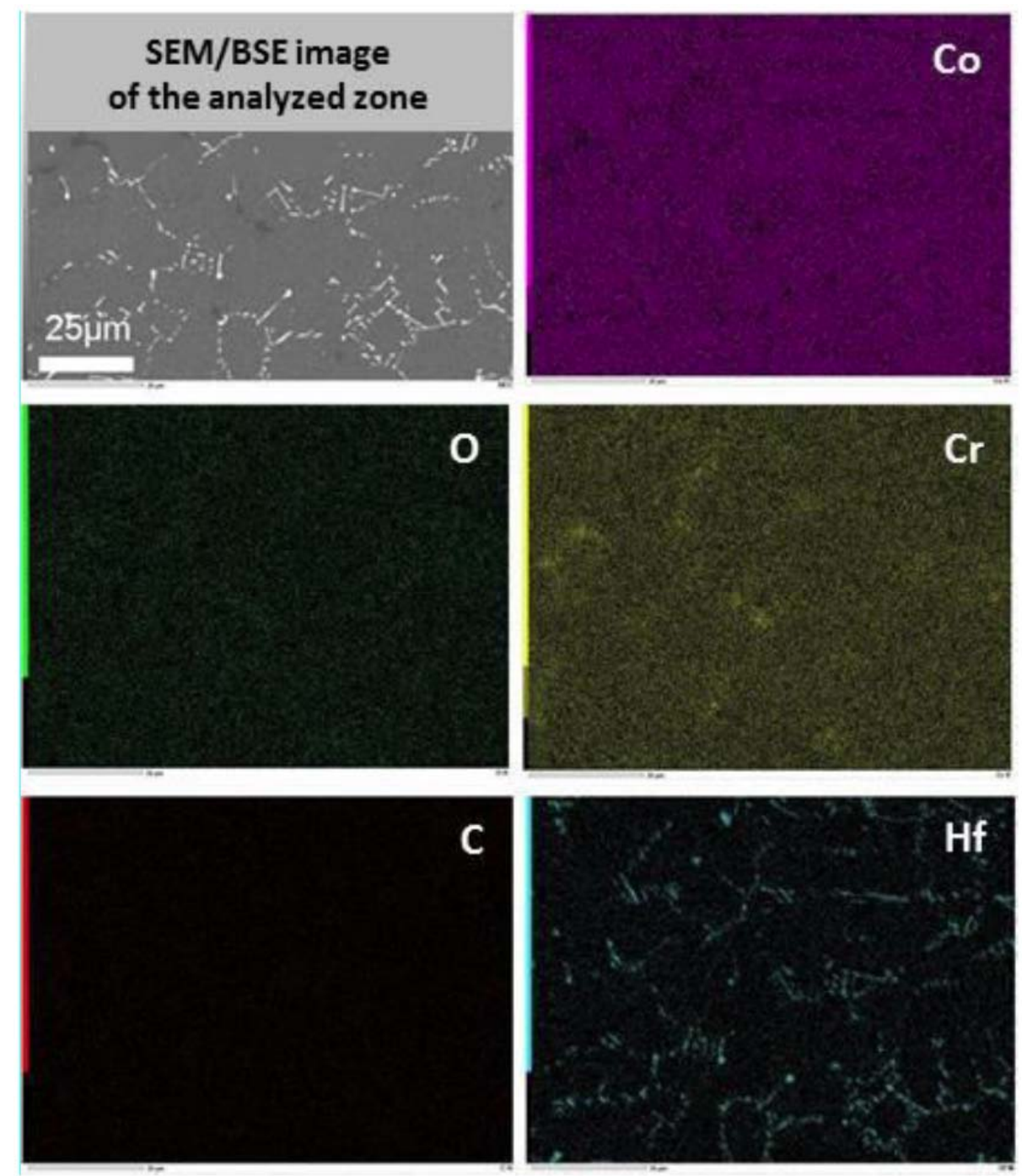

Figure 16: X-ray maps allowing distinguishing the matrix and the interdendritic carbides ( $\mathrm{HfC}$ here).
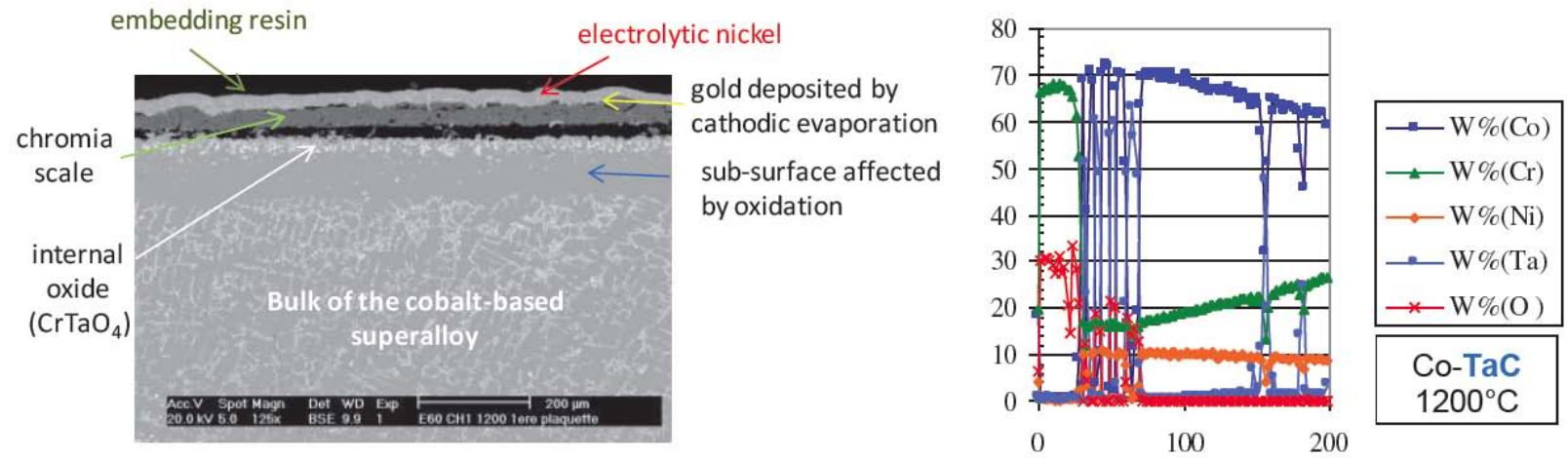

Figure 17: SEM/BSE micrograph of the subsurface of a cobalt-based alloy oxidized at high temperature (left); concentration profiles across the same zone revealing the $\mathrm{Cr}$-depletion and allowing determining an average of the $\mathrm{Cr}$ concentration gradient.

were presented here), elaborated by several different ways of fabrication and possibly reinforced by many elements and strengthening phases, display various types of microstructures. Their bulk microstructures as well as their surface and sub-surface states can be modified respectively by long exposures at high temperature and creep deformation, and by high temperature oxidation and hot corrosion involving various gas mixtures and molten substances, with as consequence a great variety of metallurgical states to 

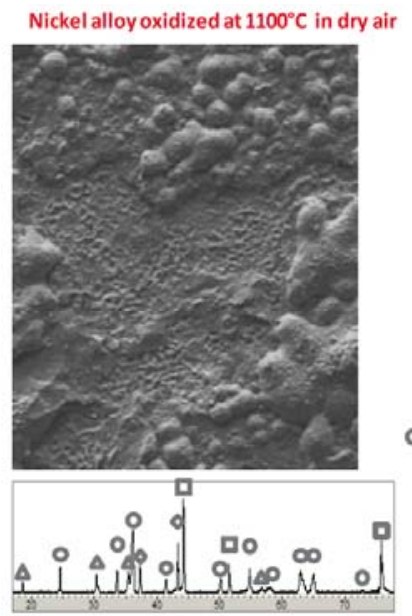

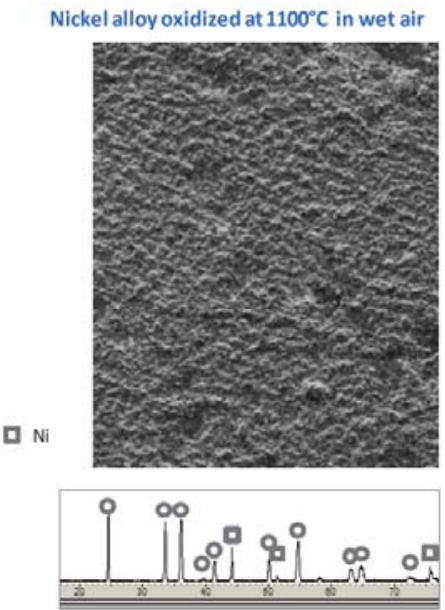

Figure 18: Observation of the difference of texture between the external oxide scales formed over a sample of nickel-based superalloy during oxidation test in two different gases, using a SEM in SE mode, X-Ray diffraction patterns allowing to identify the oxides present.

explore and understand. Fortunately many analytic techniques are available to help in this way, as briefly described here in a list of characterization means which are although not exhaustive.

\section{REFERENCES}

[1] Bradley EF. Superalloys: A Technical Guide. Metals Park: ASM International 1988.

[2] Donachie MJ, Donachie SJ. Superalloys: A Technical Guide ( $2^{\text {nd }}$ edition). Materials Park: ASM International 2002.

[3] Sims CT, Hagel WC. The superalloys. New York: John Wiley \& Sons 1972.

[4] Kosftad P. High temperature corrosion. London: Elsevier applied science 1988.
[5] Young DJ. High temperature oxidation and corrosion of metals. Amsterdam 2008.

[6] Berthod P. Kinetics of high temperature oxidation and chromia volatilization for a binary $\mathrm{Ni}-\mathrm{Cr}$ alloy. Oxidation of Metals 2005; 64(3/4): 235-252.

https://doi.org/10.1007/s11085-005-6562-8

[7] Zamoum F, Benlaharche T, David N, Podor R, Vilasi M. Kinetics of high temperature oxidation of $(\mathrm{Nb}, \mathrm{Co}, \mathrm{Cr})_{7} \mathrm{Si}_{6}$ and $(\mathrm{Nb}, \mathrm{Co}, \mathrm{Cr})_{8} \mathrm{Si}_{7}$ silicide compounds. Intermetallics 2008; 16(4): 498-507.

https://doi.org/10.1016/j.intermet.2007.12.009

[8] Di Martino J, Rapin C, Berthod P, Podor R, Steinmetz P. Corrosion of metals and alloys in molten glasses. Part 1 : glass electrochemical properties and pure metal $(\mathrm{Fe}, \mathrm{Co}, \mathrm{Ni}$, Cr) behaviours. Corrosion Science 2004; 46: 1849-1864. https://doi.org/10.1016/j.corsci.2003.10.024

[9] Chevalier S: Traitements de surface et nouveaux matériaux. Dijon: EUD 2007.

Received on 23-09-2019

Accepted on 17-10-2019

Published on 25-10-2019

DOI: https://doi.org/10.31875/2410-4701.2019.06.6

\section{(C) 2019 Patrice Berthod; Zeal Press}

This is an open access article licensed under the terms of the Creative Commons Attribution Non-Commercial License (http://creativecommons.org/licenses/by-nc/3.0/) which permits unrestricted, non-commercial use, distribution and reproduction in any medium, provided the work is properly cited. 